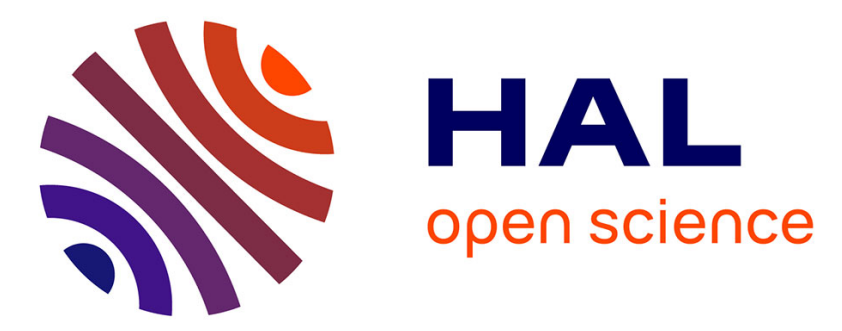

\title{
Microstructural features and local properties evolution in a heavy plastic deformed Ti-29Nb-9Ta-10Zr (wt\%) alloy
}

\author{
D. Raducanu, V.D. Cojocaru, A. Nocivin, D.M. Gordin, I. Cinca
}

\section{- To cite this version:}

D. Raducanu, V.D. Cojocaru, A. Nocivin, D.M. Gordin, I. Cinca. Microstructural features and local properties evolution in a heavy plastic deformed Ti-29Nb-9Ta-10Zr (wt\%) alloy. Materials Science and Engineering: A, 2017, 689, pp.25-33. 10.1016/j.msea.2017.02.039 . hal-01515167

HAL Id: hal-01515167

https://hal-univ-rennes1.archives-ouvertes.fr/hal-01515167

Submitted on 4 Jul 2017

HAL is a multi-disciplinary open access archive for the deposit and dissemination of scientific research documents, whether they are published or not. The documents may come from teaching and research institutions in France or abroad, or from public or private research centers.
L'archive ouverte pluridisciplinaire HAL, est destinée au dépôt et à la diffusion de documents scientifiques de niveau recherche, publiés ou non, émanant des établissements d'enseignement et de recherche français ou étrangers, des laboratoires publics ou privés. 
Microstructural features and local properties evolution in a heavy plastic deformed Ti-29Nb-9Ta$10 \mathrm{Zr}$ (wt.\%) alloy

Doina RADUCANU ${ }^{1}$, Vasile Danut COJOCARU ${ }^{1 *}$, Anna NOCIVIN ${ }^{2}$, Doina Margareta GORDIN ${ }^{3}$, Ion CINCA $^{1}$

${ }^{1}$ University Politehnica of Bucharest, Spl. Independentei 313, 060042 Bucharest, Romania

${ }^{2}$ University OVIDIUS of Constanta, Bdul. Mamaia 124, 900527 Constanta, Romania

${ }^{3}$ INSA Rennes, UMR CNRS 6226 SCR/Chimie-Métallurgie, F-35708 Rennes Cedex, France

"Corresponding author: Tel. +40-21-4029531; Fax+40-21-3169562. dan.cojocaru@mdef.pub.ro

\section{Abstract}

The microstructure, crystallographic texture and local properties evolution were investigated during thermo-mechanical processing of Ti-29Nb-9Ta-10Zr (wt.\%) alloy. The Ti-29Nb-9Ta-10Zr (wt.\%) alloy was cold-rolled by Multi-Pass Rolling (MPR) to evaluate the influence of a high intensity plastic deformation on some microstructural features (constituent phases, constitutive phase morphology, crystallographic texture) and local mechanical properties. MPR processing led to obtaining of three structural states, corresponding to a deformation degree of $60 \%, 80 \%$ and 90\%. The microstructural features were investigated by XRD and SEM techniques while the mechanical local properties were evaluated by nano-indentation. Investigations have shown that the initial microstructure consists in a mixture of parent equiaxed polyhedral $\beta$-Ti phase grains and sub-micron $\alpha^{\prime \prime}$-Ti phase dispersed inside $\beta$-Ti grains. Further, with progress of MPR processing the broad $\beta$-Ti peaks indicates heavily distorted UFC/NC $\beta$-Ti grains; also, the large and intense $\alpha^{\prime \prime}-\mathrm{Ti}$ peaks suggest the presence of NC grains and a relatively high volume fraction of $\alpha^{\prime \prime}$-Ti phase in the $\beta$-Ti matrix. MPR processing leads to development of a specific crystallographic texture; the most intense fibres were: $\gamma$-fibre, with two major components: $\{111\}<110>$ and $\{111\}<112>, \alpha$-fibre and $\varepsilon$-fibre. Also, from nano-indentation testing it was showed that local mechanical properties, such 
as instrumented elastic modulus (EIT), instrumented hardness (HIT) and Vickers microhardness $(\mathrm{HV})$, are decreasing with progress of MPR processing due to increased $\alpha^{\prime \prime}$-Ti phase fraction.

Keywords: Titanium alloys; cold deformation; texture evolution; X-ray diffraction; nanoindentation;

\section{Introduction}

Metallurgical processes such as plastic deformation associated/or not with heat treatments determine important modifications in microstructure of metallic materials, having a strongly influence upon mechanical properties. For conventional metallic materials, these processes have no considerable effects on physical properties (for instance, on elastic modulus) due to insignificant influence of thermo-mechanical processing on phenomena acting at atomic/electronic level [1]. However, in recent years, for specially designed chemical compositions $[2,3]$ associated with innovative processing methods suitable to reach nanostructures $[4,5]$ an outstanding combination of mechanical and physical properties is possible in certain metallic materials $[6,7]$, including some $\beta$-titanium alloys types $[1,8,9]$.

Properties of some alloys can be drastically changed, so that they can exhibit "super properties": simultaneously, different combinations of super cold-workability, ultra-strength, superelasticity, low elastic modulus, or Invar/ Elinvar properties [1].

A clear understanding of how these materials respond to external conditions under different situations proven to be of great importance.

For multicomponent bulk $\beta$-titanium alloys, besides an appropriate chemical composition, the processing towards nanocrystalline structures is a crucial step. Metal forming processes imposing heavy plastic deformation, termed as Severe Plastic Deformation (SPD) procedures are largely 
used to refine metallic materials structures from conventional grain sizes down to ultra-fine grained (UFG) and nanocrystalline (NC) domain [10, 11].

By SPD procedures an ultra-large plastic strain-greater than 2.0 is introduced into a bulk metallic material in order to create an ultra-fine or a nanocrystalline grain structure. So are created conditions for new phenomena development at crystalline grain level and crystal lattice level/or atomic level.

In the case of multicomponent bulk $\beta$-titanium alloys, the volume fraction and morphology of the $\alpha^{\prime \prime}$ precipitates control the strength level, while the $\beta$ grain size determines the ductility [12]. For a good strength-ductility association, the $\beta$ grain size should be refined; an appropriate tool for directing structural transformation is heavy plastic deformation provided by SPD procedures, coupled or not with recrystallization annealing.

Only in terms of cold plastic deformation mechanisms, depending on the phase stability, in $\beta$ titanium alloys can act: dislocation slip, twinning, strain-induced martensitic transformation ( $\beta$-bcc to a $\alpha^{\prime \prime}$-orthorhombic), etc. [13-16].

As concerning new phenomena developing at crystal lattice level (responsible for physical properties changes), the complex relationship between manipulations at macroscale and their effects at nanoscale/crystal lattice scale is necessary to be studied by advanced means: crystalline structure determination, qualitative and quantitative determinations of phases, identification of phase transformations, data concerning the crystalline zones, lattice parameters, micro-strains, crystal orientation.

The present study was realized to evaluate the influence of a high intensity plastic deformation at crystal lattice level for Ti-29Nb-9Ta-10Zr beta type alloy; changes accompanying deformation structure/texture and local mechanical properties were analysed.

A multi-pass rolling (MPR) was chosen as forming process available to impose sufficient strain levels to generate Ultra-Fine Crystalline (UFC)/Nanocrystalline NC structures in studied alloy. The 
aim was to promote formation of a UFC down to NC microstructure consisting in a mixture of $\beta-\mathrm{Ti}$ and $\alpha^{\prime \prime}-T i$ grains. Details of structure, texture and local mechanical properties variation after the different steps of plastic deformation process, namely, differences in the initial alloy recrystallized condition and final heavy deformed state are presented in this paper. Data concerning alloy's component phases, corresponding crystal lattice parameters were obtained based on X-ray diffraction experimental results.

In order to analyse alloy's texture after each step of plastic deformation process the $\beta$-Ti (110), (200) and (211) pole figures were measured, then fitted and analysed to calculate Inverse Pole Figures (IPF's) and Orientation Distribution Functions (ODF's). Variation of total deformation energy, instrumented hardness and instrumented elastic modulus were obtained by instrumented nano-indentation, a method widely applied to measure local mechanical properties of materials.

The present work is integrated in a larger research program in which a detailed study of structure, texture and local mechanical properties of Ti-29Nb-9Ta-10Zr beta type alloy is made in conditions in which the advanced refinement of the grain microstructure is achieved coupling severe cold deformation and subsequent recrystallization annealing. Only data concerning plastic deformation are here presented.

\section{Material and methods}

A cold crucible levitation melting technique (a FIVES CELES furnace type equipment, with nominal power $25 \mathrm{~kW}$ and melting capacity of $30 \mathrm{~cm}^{2}$ ) was used to produce the Ti-29Nb-9Ta-10Zr (\%wt) alloy, starting from high-purity elemental components. The ingot re-melting and casting was realized inside the melting furnace.

The whole thermo-mechanical processing route applied on Ti-29Nb-9Ta-10Zr alloy after casting is presented in figure 1 . For this processing route the cold rolling specific deformation degrees, as well as the parameters for heat treatments were chosen based on authors' prior results [14-16]. 
First, precursor samples were obtained by thermo-mechanical processing of the as-cast alloy to be used further to develop the multi-pass rolling (MPR) procedure. Thermo-mechanical processing consists in a homogenization heat treatment, a cold-deformation stage and a final heat treatment. The homogenization heat treatment was performed in high vacuum, at $950^{\circ} \mathrm{C}$ for 6 hours and furnace cooling, in order to obtain a homogenous structure without casting defects; the colddeformation stage was realized by applying a total thickness reduction of $60 \%$, in order to refine microstructure. Further, a heating to a temperature of $780^{\circ} \mathrm{C}$, in high vacuum for 30 minutes with subsequent cooling in water was applied to produce a completely alloy recrystallization (with a partially $\beta$ transformed), prior to multi pass rolling (MPR) procedure. This is the final step in precursor samples realization and referred into the paper as the initial state of samples subjected to severe plastic deformation by MPR. The precursor samples were cut in samples measuring $2 \mathrm{~mm} \times 20 \mathrm{~mm} \times 60 \mathrm{~mm}$ and subjected to MPR procedure by cold-rolling, in three stages, with total deformation degrees per sage of $60 \%, 80 \%$ and $90 \%$. The equivalent strain, $\varepsilon=2.42$, obtained for final deformation degree is representative for a SPD process.

In the above described experiments, the cold-rolling processes were realized using a Mario di Maio LQR120AS laboratory mill, at $3 \mathrm{~m} / \mathrm{min}$ rolling speed. The heat treatments were performed using a GERO SR 100X500/12 - high temperature laboratory furnace.

Samples in initial state and after each MPR procedure step were metallographic grinded down to 1200-grit SiC paper and polished with $6 \mu \mathrm{m}$ and $1 \mu \mathrm{m}$ polycrystalline diamond suspension followed by super-polishing with $0.02 \mu \mathrm{m}$ colloidal silica, to obtain the test surfaces for XRD, SEM microstructural analysis and instrumented nano-indentation. For all samples, the microstructure and texture examination were performed in the plane surface defined by the RD (rolling direction) and ND (normal direction).

A Philip PW 3710 diffractometer, in Bragg-Brentano $\theta-2 \theta$ geometry, using $\mathrm{Cu} K \alpha$ radiation $(\lambda=$ $1.5406 \AA$ ) was used to perform XRD characterization, to determine the phase structure and phase 
characteristics. The recorded XRD spectra were simulated and fitted. The XRD spectra simulation was performed using MAUD v2.33 software package, to calculate phases lattice parameters. For fitting procedure was used the PeakFit v4.12 software package, to determine for each peak the position, intensity and peak broadening - FWHM (Full Width at Half Maximum). A pseudo-Voigt diffraction line profile was used in fitting procedure. The SEM microstructural analysis was performed using a scanning electron microscope TESCAN VEGA II - XMU.

Alloy texture evolution in progress with MPR was investigated by XRD, using the same diffractometer fitted with an Euler cradle. The $\beta$-Ti (110), (200) and (211) Pole Figures (PF's) were measured, then, the PF's raw data were fitted and analysed, using a binning angle size of $5^{\circ} \times 5^{\circ}$, Gaussian distribution and Ghost correction by MTEX v3.2.2 software package $[17,18]$. Inverse Pole Figures (IPF's) and Orientation Distribution Functions (ODF's) were so calculated.

Nanoindentation testing was performed using a CSM NHTX S/N: 01-03279 nanoindenter fitted with a Berkovich triangular pyramidal diamond indenter. The testing was performed under a constant load of $100 \mathrm{mN}$. The nanoindenter was calibrated by using fused silica samples.

\section{Results and discussion}

\subsection{Microstructural features}

Investigations by XRD diffraction were applied on samples in so-called initial state and on samples obtained after each MPR stage (figure1). The XRD spectra were fitted in order to de-convolute the cumulative diffraction peaks in order to obtain position, intensity and broadening for each constitutive peak. Recorded XRD spectra together with detailed zooms of cumulative diffraction peaks are presented in figure 2 .

For all samples, a common feature is the presence in microstructure of a mixture of $\beta-\mathrm{Ti}$ and $\alpha^{\prime \prime}-\mathrm{Ti}$ phases. The $\beta$-Ti phase was indexed in body centred cubic system $-I m-3 m$ and the $\alpha^{\prime \prime}$-Ti phase was indexed in orthorhombic system $-\mathrm{Cmcm}$. Major diffraction peaks observed in the case of $\beta-\mathrm{Ti}$ 
phase are (110) and (211) with a special mention for (211) peak which has a significant drop in intensity beginning with the MPR process initiation. As concerning $\alpha^{\prime \prime}-$ Ti phases, major peaks are (020), (002), (220) and (202). To investigate this situation, detailed zooms of cumulative diffraction peaks corresponding to $2 \theta=\left(36^{\circ}-41^{\circ}\right)$ and $2 \theta=\left(66^{\circ}-74^{\circ}\right)$ scattering angles were realized for all samples (figures 2.a to 2.d).

For all samples, in $2 \theta=\left(36^{\circ}-41^{\circ}\right)$ scattering domain, the following peaks sequence is observed: $\alpha^{\prime \prime}(020)-\beta(110)-\alpha^{\prime \prime}(002)$ with their global Intensity decreasing from sample in initial state to sample with maximum deformation degree (90\%). In $2 \theta=\left(30^{\circ}-40^{\circ}\right)$ scattering domain the peaks sequence is changing compared with those previously presented, but some similarities inside explored domain are observed; for example, the same peak sequence is observed for samples in initial state and sample with maximum cold-rolling degree (90\%): $\alpha^{\prime \prime}(220)-\beta(211)-\alpha^{\prime \prime}(202)$, but with quite different intensities. Another similarity concerns samples with intermediate rolling degrees, $60 \%$ and $80 \%$, respectively. The peak sequence is in this case $\beta(211)-\alpha^{\prime \prime}(220)-\alpha^{\prime \prime}(202)$.

The lattice parameters in the case of both, $\beta$-Ti and $\alpha^{\prime \prime}$-Ti phases were calculated based on data concerning peaks position. Obtained data are here presented. For $\beta$-Ti phase, calculated lattice parameter is $a=3.30 \AA ̊$, having the same value for alloy in initial state and for alloy deformed with $60 \%$ deformation degree; for alloy deformed with $80 \%$ and $90 \%$ deformation degrees calculated lattice parameter is $a=3.29 \AA$. Some differences in calculated lattice parameter for $\alpha^{\prime \prime}$-Ti phase are observed for alloy in different conditions. For alloy in initial state, $\alpha^{\prime \prime}-$ Ti phase has the following lattice parameters $a=3.30 \AA ; \quad b=4.77 \AA$ and $c=4.67 \AA$, while for MPR states the lattice parameters are $=3.21 \AA ; \quad b=4.70 \AA$ and $c=4.60 \AA$. .

According with other scientific results [19], the broad $\beta$-Ti peaks in the case of the alloy processed by MPR , indicate heavily distorted UFC/NC $\beta$-Ti grains; the large and intense $\alpha^{\prime \prime}$-Ti peaks suggest NC grains and a relatively high volume fraction of $\alpha^{\prime \prime}-T i$ phase present in the $\beta$-Ti matrix. Thus, it 
follows a bimodal microstructure. It is hypothesized that $\alpha^{\prime \prime}$-Ti martensite is a stress induced type, caused by heavy cold-rolling in MPR process.

The microstructure of all investigated samples is presented in figure 3. Initial state sample (figure 3.a) shows the presence of equiaxed polyhedral $\beta$-Ti grains, with an average grain-size close to $46 \mu \mathrm{m}$, with sub-micron $\alpha^{\prime \prime}$-Ti phase dispersed inside $\beta$-Ti grains. The samples obtained by MPR processing with rolling degrees of $60 \%$ (figure 3.b), of $80 \%$ (figure 3.c) and of $90 \%$ (figure 3.d) show how initial equiaxed polyhedral $\beta$-Ti grains are becoming more elongated along RD direction and fragmented due shear deformation. As observed, the microstructure exhibits a pronounced deformation texture with intense deformed elongated grains aligned along RD direction, more intense with progress of MPR processing.

\subsection{Crystallographic texture analysis}

Alloy texture evolution in progress with MPR process is based on the analysis only of $\beta$-Ti phase texture; for $\alpha^{\prime \prime}$-Ti phase, high difficulties appear in acquiring Pole Figures (PF's). The $\beta$-Ti pole figures (110), (200) and (211) were measured by XRD. Pole figures and further transformations were realized taking into account, besides crystal reference frame (indexed in cubic $I m-3 m$ system), the sample reference frame (indexed in orthorhombic $\mathrm{mmm}$ system): [100] - rolling direction (RD); [010] - transversal direction (TD) and [001] - normal direction (ND). Based on raw pole figures data, the Inverse Pole Figures (IPF's) and Orientation Distribution Functions (ODF's) were calculated and plotted.

Figure 4 shows the IPF's for RD, TD and ND directions in the case of samples with $60 \%$ deformation degree (figure 4.a), 80\% deformation degree (figure 4.b) and 90\% deformation degree (figure 4.c); they indicate how the selected direction in the sample reference frame is distributed in the reference frame of the crystal. Each IPF shows which crystallographic directions in the polycrystalline material are parallel with the specific sample rolling direction. 
For each sage of MPR process, one can see that the [111]//ND pair reaches the highest MROD (multiples of a random orientation distribution) intensity close to 4.0, followed by [100]//ND pair starting with about 3.5 MROD for sample with 60\% deformation degree (figure 4.a) and varying to 4.2 and respectively 3.5 for sample with $80 \%$ deformation degree and reaching 5.0 to 3.5 for sample with $90 \%$ deformation degree. For RD and TD sample directions, lower MROD intensities are observable, no matter crystallographic directions and sample condition. [110]//TD pair has, although, significant MROD intensities of about 1.5 for sample with $60 \%$ deformation degree (Figure 4.a) and 2.1-2.2 MROD for samples with $80 \%$ and $90 \%$ deformation degrees (figure 4.b, 4.c). Lowest MROD intensities are observable for [112] //RD pair.

Concluding, the following three pairs [111]//ND, [100]//ND, [110]//TD are representative and the developed texture in MPR process consist in fallowing components: [001]//ND ( $\theta$-fibre), [111]//ND $(\gamma$-fibre) and [011]//RD ( $\alpha$-fibre) [20-22].

In the next step, based on PF's data, the ODF's were calculated and plotted, taking into account that crystallographic texture can be represented in the reduced Euler space using the Bunge system $\left(\phi_{1}-\Phi-\phi_{2}\right)\left(\phi_{1}=\left(0^{\circ}-90^{\circ}\right) ; \Phi=\left(0^{\circ}-90^{\circ}\right) ; \phi_{2}=\left(0^{\circ}-90^{\circ}\right)\right.$ and the fact that, for bcc metals, the most important texture fibres are well defined $[23,24]$.

Relevant ODF's sections corresponding to rotation angles of $\phi_{2}=0^{\circ}$ and of $\phi_{2}=45^{\circ}$ are usually reported in the case of bcc metals.

In figure 5 are presented calculated ODF's sections (corresponding to $\phi_{2}=0^{\circ}$ and $\phi_{2}=45^{\circ}$ angles) for MPR processed alloy. One can see that a rather complicated mixture of texture components is present, with a special mention for ODF sections at $\varphi_{2}=45^{\circ}$ (figure 5.a, 5.b, 5.c) where high MROD intensities are identified.

For ODF's sections at $\varphi_{2}=45^{\circ}$ the development of a strong $\gamma$-fibre is relevant, accompanied of $\alpha$ fibre and $\varepsilon$-fibre of less MROD intensities. The $\gamma$-fibre has two major components: $\{111\}<110>$ and $\{111\}<112>$. However, both components are very strong in terms of MROD intensities (high values 
were observed, from 4.5 to 5), their evolution with MPR process progress being quite opposite. So, the $\{111\}<110>$ component has a maximum for $80 \%$ deformation degree (about 4.4 MROD) meanwhile the $\{111\}<112>$ component reaches a minimum (about 3.7 MROD). This situation is more suggestive illustrated by ODF calculated differences between: sample with $60 \%$ deformation degree and sample with $80 \%$ deformation degree (figure 6.a) and also for sample with $80 \%$ deformation degree and sample with 90\% deformation degree, respectively (figure 6.b).

As concerning $\alpha$-fibre, with textural component $\{001\}<110>$, a continuous decrease (from 4.5 to 3.5 MROD) with MPR progress is observable. The $\varepsilon$-fibre $(\{112\}<111>$ textural component $)$ is less strong, with MROD intensities varying from 2.4 to 3.6 with MPR progress. Other components observed for ODF sections at $\varphi_{2}=0^{\circ}$ (figure 5) are of minor interest.

Even the ODF supplies a detailed description of crystallographic texture components of grains in polycrystalline materials (a component $g$ being defined by the angles $\varphi_{1}, \Phi$ and $\varphi_{2}$ that correspond to a rotation about $Z-X-Z$-axes in the Bunge system [24]), advanced texture data processing concerning textured volume with same modal orientation and texture index are necessary to have an accurate image about texture evolution. These data are calculated and presented in table 1.

A continuous growth of calculated parameters corresponding for samples resulted from MPR process is noticed, this situation indicating the texture strengthening; i.e., the texture index increases from 1.46 , in the case of sample with $60 \%$ deformation degree, to 1.88 in the case of sample with $90 \%$ deformation degree (see table 1 ).

As observed, textured volume with same modal orientation increases with progress of MPR processing, if are taking into account the two major components of $\gamma$-fibre: $\{111\}<110>$ and $\{111\}<112>$; it can be observed that the highest textured volume with same modal orientation is present in the case of $\{111\}<110>$ components for sample with $60 \%$ deformation degree (up to $8.14 \%-8.16 \%$ ) and for sample with $80 \%$ deformation degree (up to $8.83 \%-8.84 \%$ ), while in the chase of sample with $90 \%$ deformation degree the highest textured volume with same modal 
orientation is observed for $\{111\}<112>$ components (up to $11.21 \%-11.32 \%$ ), indicating an increased texture strengthening at high plastic deformation degrees.

This texture strengthening was ascribed to deformation accumulation in regions of high stored energy [15], being in agreement with results of previous works [15]. Besides these observations, the orientation relationship between different deformed zones remains to be studied further to clarify which possible mechanisms are acting: dislocation, slip, twining, giant faults, etc. [16].

\subsection{Nanoindentation analysis}

The nano-indentation (NI) technique was employed to obtain data about local mechanical properties evolution with MPR progress. Load-indentation depth values (experimentally obtained) were the input data to evaluate the variation of total deformation/indentation energy, instrumented elastic modulus (EIT) and instrumented hardness (HIT).

The instrumented hardness (HIT) and instrumented elastic modulus (EIT) were estimated from the initial gradient of the unloading curves using the Oliver and Pharr [25-27] model.

In nano-indentation, hardness is obtained by dividing the maximum applied load by the projected area of contact taking into consideration that the known geometry of the indenter coupled with the depth of penetration offer an indirect measure of the projected area of contact at maximum load.

In figures 7, 8, 9 are presented experimental data concerning load-indentation depth curves and data referring to deformation/indentation energy, instrumented elastic modulus (EIT), instrumented hardness (HIT) and Vickers microhardness (HV) variation for samples of Ti-29Nb-9Ta$10 Z$ r alloy processed by MPR.

Figure 7.a shows a typical profile of a load-indentation depth curve obtained during nanoindentation testing. 
Load-displacement curves during the $\mathrm{NI}$ experiments have the same profile for all samples but show different final indentation depth values and also different loading-unloading paths (figure 7.b). One can observe that at maximum load, of $100 \mathrm{mN}$, the maximum indentation depth increases with progress of MPR, the highest indentation depth being obtained in the case of sample with $90 \%$ deformation degree. This explains the variation of total energy which shows a continuous growth with progress of cold-rolling deformation as a consequence of plastic deformation energy stored after each rolling stage (figure 8a, 8.b, 8.c). EIT, HIT and Vickers microhardness (HV) respectively, have an inverse evolution, decreasing with cold rolling degree (figure 9.a, 9.b, 9.c), i.e. EIT continuously decreases form $\sim 75 \mathrm{GPa}$, corresponding to sample in initial state, to $\sim 20 \mathrm{GPa}$ corresponding to sample with $90 \%$ deformation degree.

This behaviour can be explained by three competitive mechanisms; the first refers to phase balance influence, respectively to increased quantity of $\alpha^{\prime \prime}$-Ti phase, being known that $\alpha^{\prime \prime}$-Ti phase exhibits much lower EIT, HIT and HV values in comparison with parent $\beta$-Ti phase [28]; so, increasing the $\alpha^{\prime \prime}$-Ti phase fraction will results in a decreasing of $\mathrm{NI}$ properties.

The second mechanism refers to presence of UFC/NC grains, as a result of heavy cold-rolling deformation, leading to increasing NI properties via Hall-Petch influence [29]. The third mechanism assumes the presence of an increased dislocation density, which increases alloy's strengthening, and ultimately NI properties [30]. All three mechanisms are strongly influenced by the progress of cold-rolling, resulting a higher fraction of $\alpha^{\prime \prime}$-Ti phase, smaller grain-sizes of both $\beta$ Ti and $\alpha^{\prime \prime}$-Ti phases and an increased dislocation density.

\section{Conclusions}

The general aim of this study was to contribute to a detailed understanding of specific development of crystallographic relations occurring in quaternary beta Titanium alloys when subjected to severe plastic deformation, in this case a MPR type. 
The present study was conducted to highlight specific data concerning microstructural features, crystallographic texture evolution and local mechanical properties variations determined by processing MPR.

As concerning microstructural transformations, a common feature is a mixture of $\beta-\mathrm{Ti}$ and $\alpha^{\prime \prime}-\mathrm{Ti}$ phases in Ti-29Nb-9Ta-10Zr alloy, with a relatively high volume fraction of $\alpha^{\prime \prime}$-Ti phase present in the $\beta$-Ti matrix phase for alloy in MPR processed state.

Texture analysis shows texture strengthening along MPR process, expressed by high textured volume with same modal orientation and texture index, which can be explained by deformation accumulation in regions of high stored energy; this is proved, also, by total energy stored after each MPR stage which shows a continuous growth.

Local mechanical properties expressed by Instrumented Elastic Modulus (EIM) and Instrumented Hardness (HIT) respectively, have as common feature a continuous decreasing with progress of MPR processing.

Besides these observations, the orientation relationship determined by the progress of SPD /PMR should be completed by further studies aimed to clarify which possible mechanisms are acting: dislocation, slip, twining, giant faults, etc.

At this stage, the present study provides useful information to design a processing route for quaternary Titanium alloys, Ti-Nb-Ta-Zr type, capable of generating microstructure transformations and strong textures.

\section{Acknowledgements}

This work was supported by an internal research grant of University POLITEHNICA of Bucharest GEX 53/2016 cod 224 - Materiale cu proprietati de ultra-rezistenta. 


\section{References}

[1] T. Saito, T. Furuta, J.H. Hwang, et al., Multifunctional alloys obtained via a dislocation-free plastic deformation mechanism, Science 300 (2003) 464-467.

[2] P. Laheurte, F. Prima, A. Eberhardt, T. Gloriant, M. Wary, E. Patoor, Mechanical properties of low modulus $\beta$ titanium alloys designed from the electronic approach, J. Mech. Behav. Biomed. Mater. 3 (2010) 565-573.

[3] M. Morinaga, et al., Theoretical design of titanium alloys, The 6th World Conference on Titanium, Cannes, France, (1988) 1601-06.

[4] T. Sleboda, K. Muszka, J. Majta, P. Hale, R.N. Wright, The possibilities of mechanical property control in fine grained structures, J. Mater. Process. Technol. 177 (2006) 461-464.

[5] S. Suresh, J. Li, Deformation of the ultra-strong, Nature 456 (2008) 716-717.

[6] Z.W. Shan, R.K. Mishra, S.A. Syed Asif, O.L. Warren, A.M. Minor, Mechanical annealing and source-limited deformation in submicrometre - diameter Ni crystals, Nat. Mater. 7 (2008) 115-119. [7] J.R. Greer, J.Th.M. De Hosson, Plasticity in small-sized metallic systems: Intrisnsic versus extrinsic size effect, Prog. Mater. Sci. 56 (2011) 654-724.

[8] D.K. Yang, P.D. Hodgson, C.E. Wen, Simultaneously enhanced strength and ductility of titanium via multimodal grain structure, Scripta Mater. 63 (2010) 941-944.

[9] S.J. Li, T.C. Cui, Y.L. Li, Y.L. Hao, R. Yang, Ultrafine-grained $\beta$-type titanium alloy with nonlinear elasticity and high ductility, Appl. Phys. Lett. 92 (2008) 043128.

[10] Y.T. Zhu, T.C. Lowe, T.G. Langdon, Performance and applications of nanostructured materials produced by severe plastic deformation, Scripta Mater. 51 (2004) 825-830.

[11] A. Azushima, R. Kopp, A. Korhonen, et.al., Severe plastic deformation (SPD) processes for metals, CIRP Ann. 57 (2008) 716-735. 
[12] O.M. Ivasishin, P.E. Markovsky, Y.V. Matviychuk, S.L. Semiatin, C.H. Ward, S. Fox, A comparative study of the mechanical properties of high-strength $\beta$-titanium alloys, J. Alloys Compd. 457 (2008) 296-209.

[13] M.H Cai, C.Y. Lee, S. Kang, Y.K. Lee, Fine-grained structure fabricated by strain-induced martensite and its reverse transformations in a metastable b titanium alloy, Scripta Mater. 64 (2011) 1098-1101.

[14] VD. Cojocaru, D. Raducanu, D.M. Gordin, I. Cinca, Texture evolution during ARB (Accumulative Roll Bonding) processing of Ti-10Zr-5Nb-5Ta alloy, J. Alloys Compd. 546 (2013) 260-269.

[15] V.D. Cojocaru, D. Raducanu, T. Gloriant, D.M. Gordin, I. Cinca, Effects of cold-rolling deformation on texture evolution and mechanical properties of Ti-29Nb-9Ta-10Zr alloy, Mater. Sci. Eng., A 586 (2013) 1-10.

[16] M. Tane, S. Akita, T. Nakano, K. Hagihara, Y. Umakoshi, M. Niinomi, H. Mori, H. Nakajima, Low Young's modulus of $\mathrm{Ti}-\mathrm{Nb}-\mathrm{Ta}-\mathrm{Zr}$ alloys caused by softening in shear moduli $\mathrm{c}^{\prime}$ and $\mathrm{c} 44$ near lower limit of body-centered cubic phase stability, Acta Mater. 58 (2010) 6790-6798.

[17] F. Bachmann, R. Hielscher, H. Schaeben, Texture analysis with MTEX - free and Open Source Software Toolbox, Solid State Phenom. 160 (2010) 63-68.

[18] F. Bachmann, R. Hielscher, P.E. Jupp, W. Pantleon, H. Schaeben, E. Wegert, Inferential statistics of electron backscatter diffraction data from within individual crystalline grains, J. Appl. Crystallogr. 43 (2010) 1338-1355.

[19] F. Sun, S. Nowak, T. Gloriant, P. Laheurte, A. Eberhardt, F. Prima, Influence of a short thermal treatment on the superelastic properties of a titanium-based alloy, Scripta Mater. 63 (2010) 10531056.

[20] M. Holscher, D. Raabe, K. Lucke, Relationship between rolling textures and shear textures in f.c.c. and b.c.c. metals, Acta Metall. Mater. 42 (1994) 879-886.

[21] D. Raabe, K. Lucke, Textures of ferritic stainless steels, Mater. Sci. Technol. 9 (1993) 302-312. 
[22] B. Sander, D. Raabe, Texture inhomogeneity in a Ti-Nb-based $\beta$-titanium alloy after warm rolling and recrystallization, Mat. Sci. Eng., A 479 (2008) 236-247.

[23] L. Wang, W. Lu, J. Qin, F. Zhang, D. Zhang, Texture and superelastic behavior of cold-rolled TiNbTaZr alloy, Mater. Sci. Eng., A 491 (2008) 372-377.

[24] T. Inamura, Y. Kinoshita, J.I. Kim, H.Y. Kim, H. Hosoda, K. Wakashima, S. Miyazaki, Effect of $\{001\}<110>$ texture on superelastic strain of Ti-Nb-Al biomedical shape memory alloys, Mater. Sci. Eng., A 438-440 (2006) 865-869.

[25] W.C. Oliver and G.M. Pharr, Improved technique for determining hardness and elastic modulus using load and displacement sensing indentation experiments, J. Mater. Res. 7 (1992) 1564-1580.

[26] W.C. Oliver and G.M. Pharr, Measurement of hardness and elastic modulus by instrumented indentation: advances in understanding and refinements to methodology, J. Mater. Res. 19 (2004) 3-20.

[27] A.C. Fischer-Cripps, Critical review of analysis and interpretation of nanoindentation test data, Surf. Coat. Technol. 200 (2006) 4153-4165.

[28] L. Wang, W. Lu, J. Qin, F. Zhang, D. Zhang, Microstructure and mechanical properties of coldrolled TiNbTaZr biomedical $\beta$ titanium alloy, Mater. Sci. Eng. A 490 (2008) 421-426.

[29] O. Ertorer, T. Topping, Y. Li, W. Moss, E.J. Lavernia, Enhanced tensile strength and high ductility in cryomilled commercially pure titanium, Scripta Mater. 60 (2009) 586-589.

[30] Y.F. Xu, D.Q. Yi, H.Q. Liu, X.Y. Wu, B. Wang, F.L. Yang, Effects of cold deformation on microstructure, texture evolution and mechanical properties of Ti-Nb-Ta-Zr-Fe alloy for biomedical applications, Mater. Sci. Eng. A 547 (2012) 64-71. 
Figure 1. Thermo-mechanical processing route applied on Ti29Nb-9Ta-10Zr alloy.

Figure 2. XRD spectra corresponding to initial state of Ti29Nb-9Ta-10Zr alloy (a); 60\% cold-rolled Ti-29Nb-9Ta-10Zr alloy (b); $80 \%$ cold-rolled Ti-29Nb-9Ta-10Zr alloy (c); $90 \%$ cold-rolled Ti-29Nb9Ta-10Zr alloy (d).

Figure 3. SEM-BSE images corresponding to initial state of Ti29Nb-9Ta-10Zr alloy (a); $60 \%$ coldrolled Ti-29Nb-9Ta-10Zr alloy (b); 80\% cold-rolled Ti-29Nb-9Ta-10Zr alloy (c); $90 \%$ cold-rolled Ti29Nb-9Ta-10Zr alloy (d).

Figure 4. Representation of IPF's for: $60 \%$ cold-rolled Ti-29Nb-9Ta-10Zr alloy (a); $80 \%$ cold-rolled Ti-29Nb-9Ta-10Zr alloy (b); 90\% cold-rolled Ti-29Nb-9Ta-10Zr alloy (c).

Figure 5. Representation of ODF's sections $\varphi_{2}=0^{\circ}$ and $\varphi_{2}=45^{\circ}: 60 \%$ cold-rolled Ti-29Nb-9Ta-10Zr alloy (a); $80 \%$ cold-rolled Ti-29Nb-9Ta-10Zr alloy (b); $90 \%$ cold-rolled Ti-29Nb-9Ta-10Zr alloy (c).

Figure 6. Representation of ODF's sections $\varphi_{2}=0^{\circ}$ and $\varphi_{2}=45^{\circ}$; differences between $60 \%$ coldrolled and $80 \%$ cold-rolled Ti-29Nb-9Ta-10Zr alloy (a); differences between $80 \%$ cold-rolled and 90\% cold-rolled Ti-29Nb-9Ta-10Zr alloy (b).

Figure 7. Load - indentation depth curves of processed Ti-29Nb-9Ta-10Zr alloy; a - typical aspect of a loading - unloading nano-indentation curve; $b$ - loading - unloading nano-indentation curves of all processed states.

Figure 8. Characteristic energy variation of processed Ti-29Nb-9Ta-10Zr alloy; variation of plastic energy $(W p)(a)$; variation of elastic energy (We) (b); variation of total energy (Wt) (c).

Figure 9. Representation of computed nano-indentation parameters of processed Ti-29Nb-9Ta10Zr alloy; Instrumented Elastic Modulus (EIM) (a); Instrumented Hardness (HIT) (b); Vickers microhardness (HV) (c). 
Table 1. Texture characteristics of TM Ti-29Nb-9Ta-10Zr processed alloy.

\begin{tabular}{|c|c|c|c|c|c|c|}
\hline \multirow[t]{2}{*}{ Sample state } & \multicolumn{3}{|c|}{$\begin{array}{l}\text { Modal orientation } \\
\text { (MO) }\end{array}$} & \multirow{2}{*}{$\begin{array}{l}\text { Texture component } \\
\quad\{h k l\}<u v w>\end{array}$} & \multirow{2}{*}{$\begin{array}{c}\text { Textured volume } \\
\text { with same MO } \\
{[\%]}\end{array}$} & \multirow[t]{2}{*}{ Texture index } \\
\hline & $\phi_{1}\left[^{\circ}\right]$ & $\Phi\left[^{\circ}\right]$ & $\phi_{2}\left[^{\circ}\right]$ & & & \\
\hline \multirow{6}{*}{$60 \%$ cold-rolled } & 90 & 0 & 45 & $\{001\}<\overline{1} \overline{1} 0>$ & 3.93 & \multirow{6}{*}{1.46} \\
\hline & 90 & 30 & 45 & $\{112\}<\overline{1} \overline{1} 1>$ & 4.82 & \\
\hline & 0 & 55 & 45 & $\{111\}<1 \overline{1} 0>$ & 8.14 & \\
\hline & 30 & 55 & 45 & $\{111\}<1 \overline{2} 1>$ & 7.84 & \\
\hline & 60 & 55 & 45 & $\{111\}<0 \overline{1} 1>$ & 8.16 & \\
\hline & 90 & 55 & 45 & $\{111\}<\overline{1} \overline{1} 2>$ & 7.75 & \\
\hline \multirow{6}{*}{$80 \%$ cold-rolled } & 90 & 0 & 45 & $\{001\}<\overline{1} \overline{1} 0>$ & 3.71 & \multirow{6}{*}{1.57} \\
\hline & 90 & 30 & 45 & $\{112\}<\overline{1} \overline{1} 1>$ & 6.52 & \\
\hline & 0 & 55 & 45 & $\{111\}<1 \overline{1} 0>$ & 8.83 & \\
\hline & 30 & 55 & 45 & $\{111\}<1 \overline{2} 1>$ & 8.35 & \\
\hline & 60 & 55 & 45 & $\{111\}<0 \overline{1} 1>$ & 8.84 & \\
\hline & 90 & 55 & 45 & $\{111\}<\overline{1} \overline{1} 2>$ & 8.24 & \\
\hline \multirow{6}{*}{$90 \%$ cold-rolled } & 90 & 0 & 45 & $\{001\}<\overline{1} \overline{1} 0>$ & 3.22 & \multirow{6}{*}{1.88} \\
\hline & 90 & 30 & 45 & $\{112\}<\overline{1} \overline{1} 1>$ & 7.11 & \\
\hline & 0 & 55 & 45 & $\{111\}<1 \overline{1} 0>$ & 10.77 & \\
\hline & 30 & 55 & 45 & $\{111\}<1 \overline{2} 1>$ & 11.32 & \\
\hline & 60 & 55 & 45 & $\{111\}<0 \overline{1} 1>$ & 10.81 & \\
\hline & 90 & 55 & 45 & $\{111\}<\overline{1} \overline{1} 2>$ & 11.21 & \\
\hline
\end{tabular}




\section{Ti-29Nb-9Ta-10Zr (wt. \%) \\ Synthesis (cold crucible induction in levitation)}

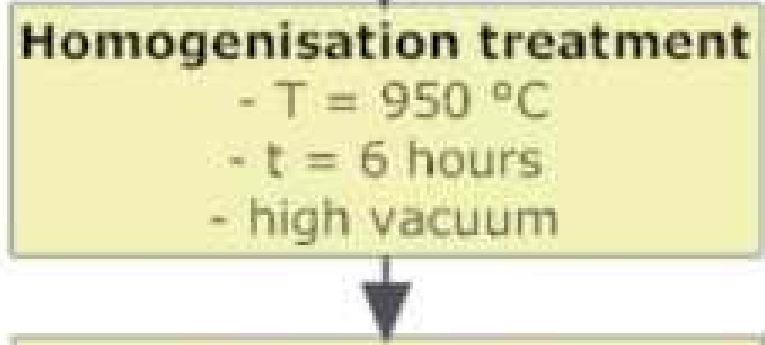

\section{Cold-rolling:}

- thickness reduction:

$$
\varepsilon=60 \%
$$

\section{Recrystallization +} water quenching

$-\mathrm{T}=780^{\circ} \mathrm{C}$

$-\mathrm{t}=30 \mathrm{~min}$

- high vacuum

- cooling: cold water

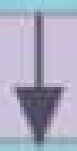

\section{Cold-rolling:}

- thickness reduction:

$$
\varepsilon=60 \%
$$

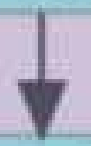

\section{Cold-rolling:}

- thickness reduction:

$$
5=80 \%
$$

\section{$\mathbf{8 0} \%$ cold-rolled}

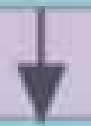

\section{Cold-rolling:}

- thickness reduction:

$$
E=90 \%
$$

$90 \%$ cold-rolled 

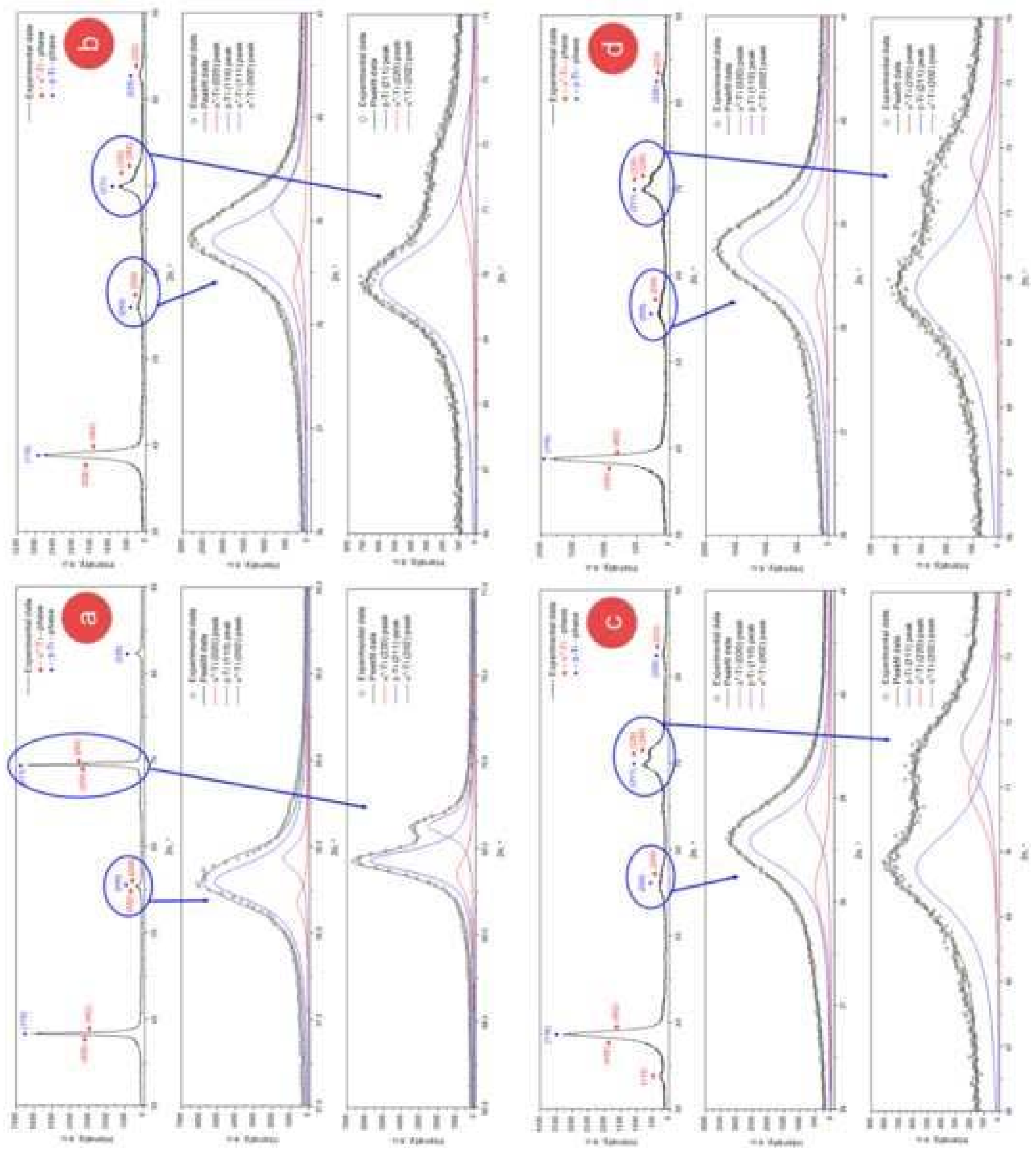


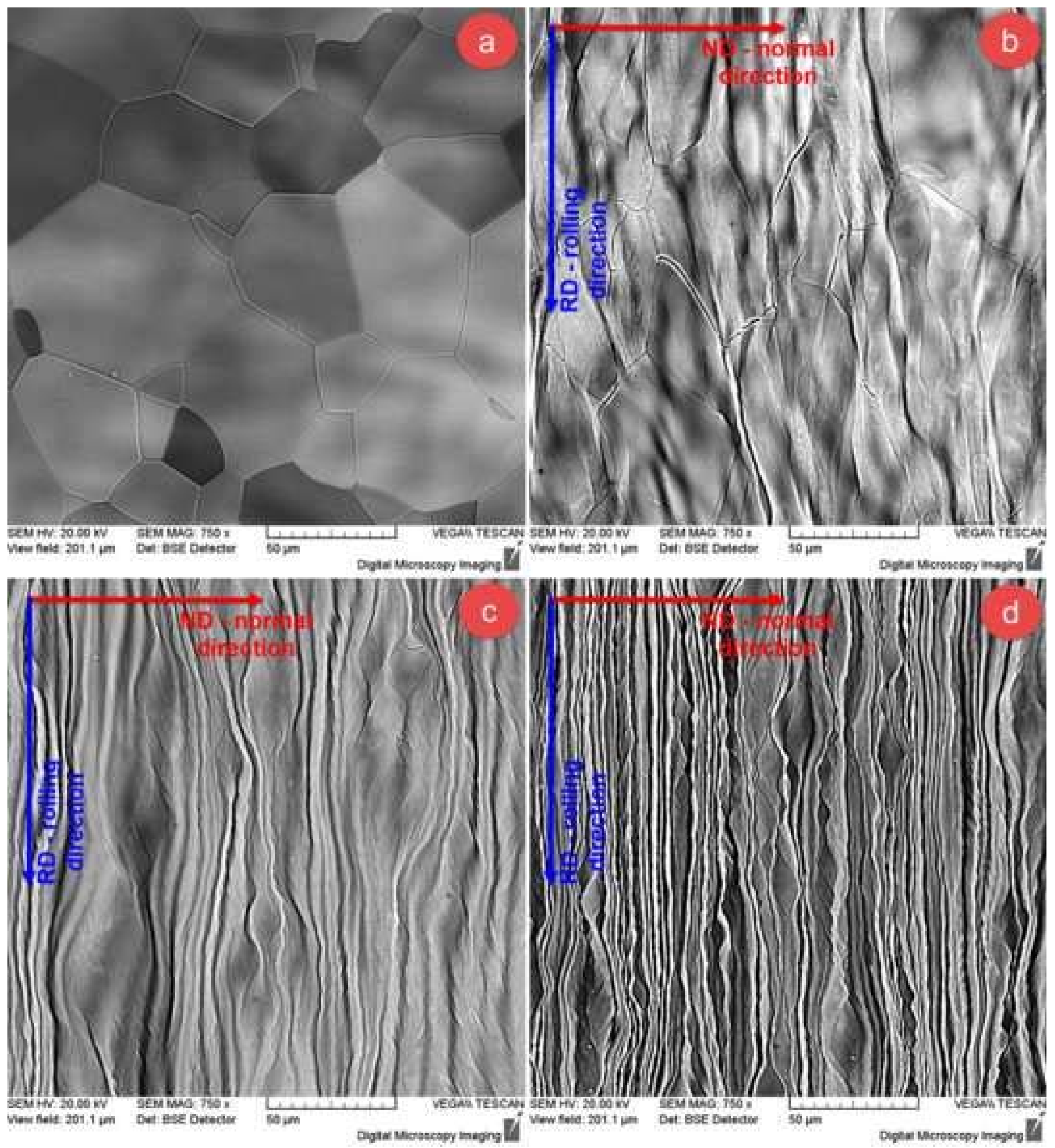



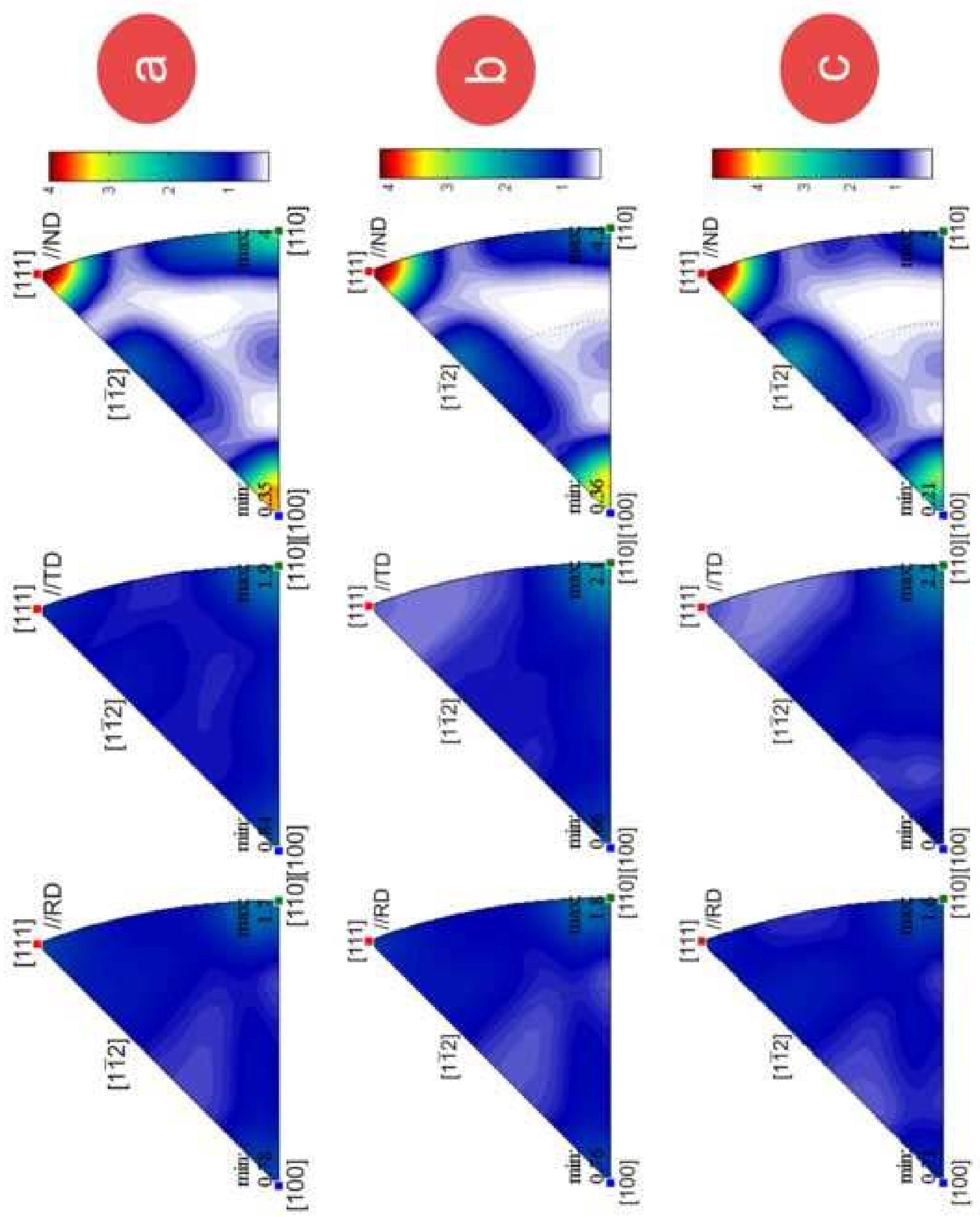

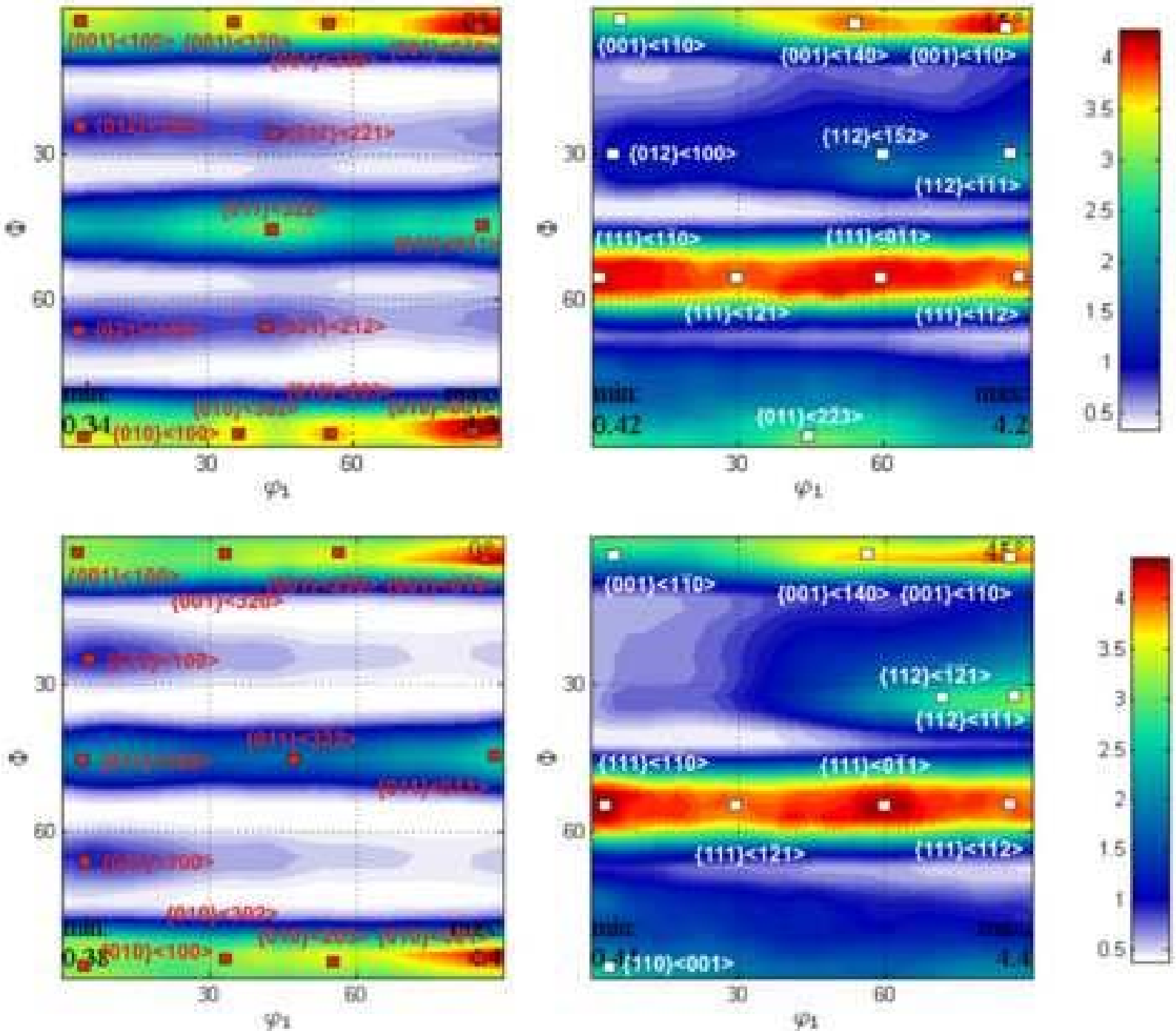

b
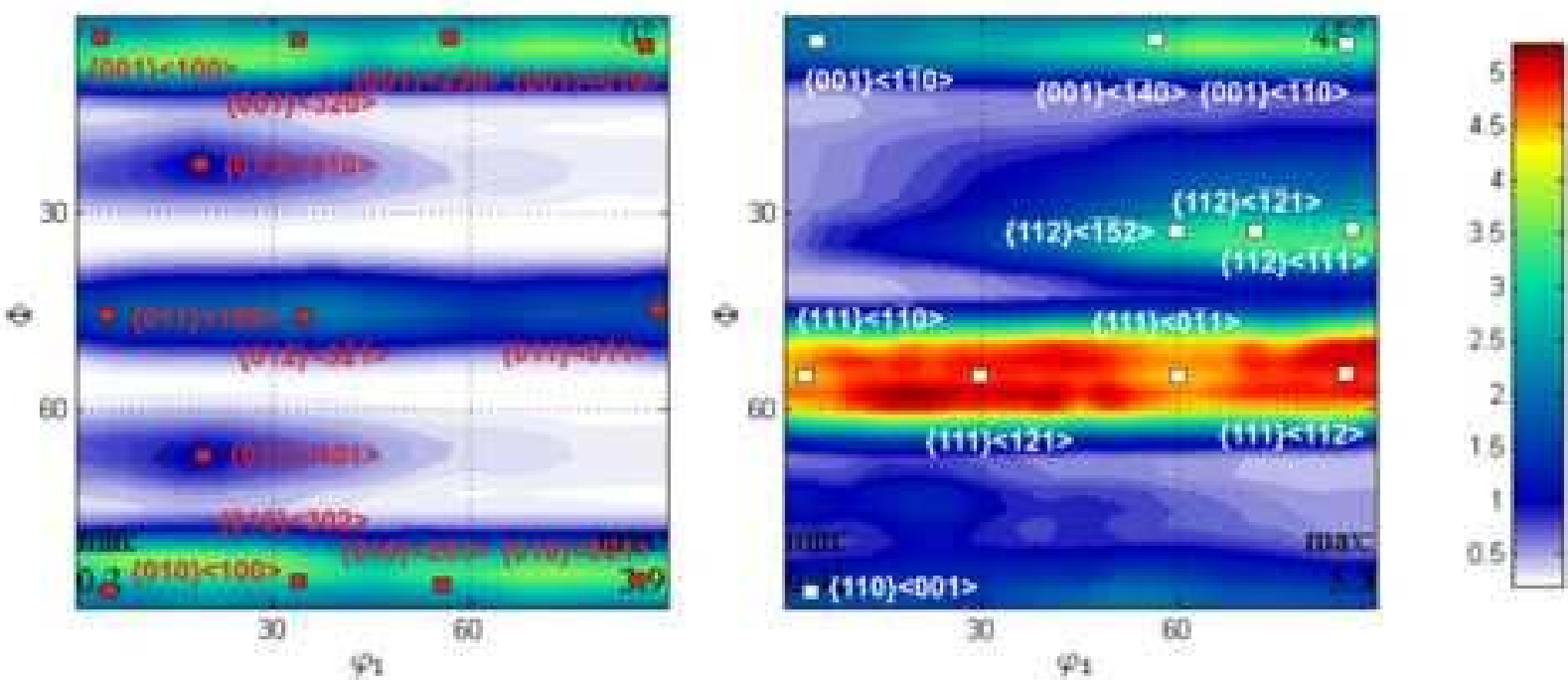

8 

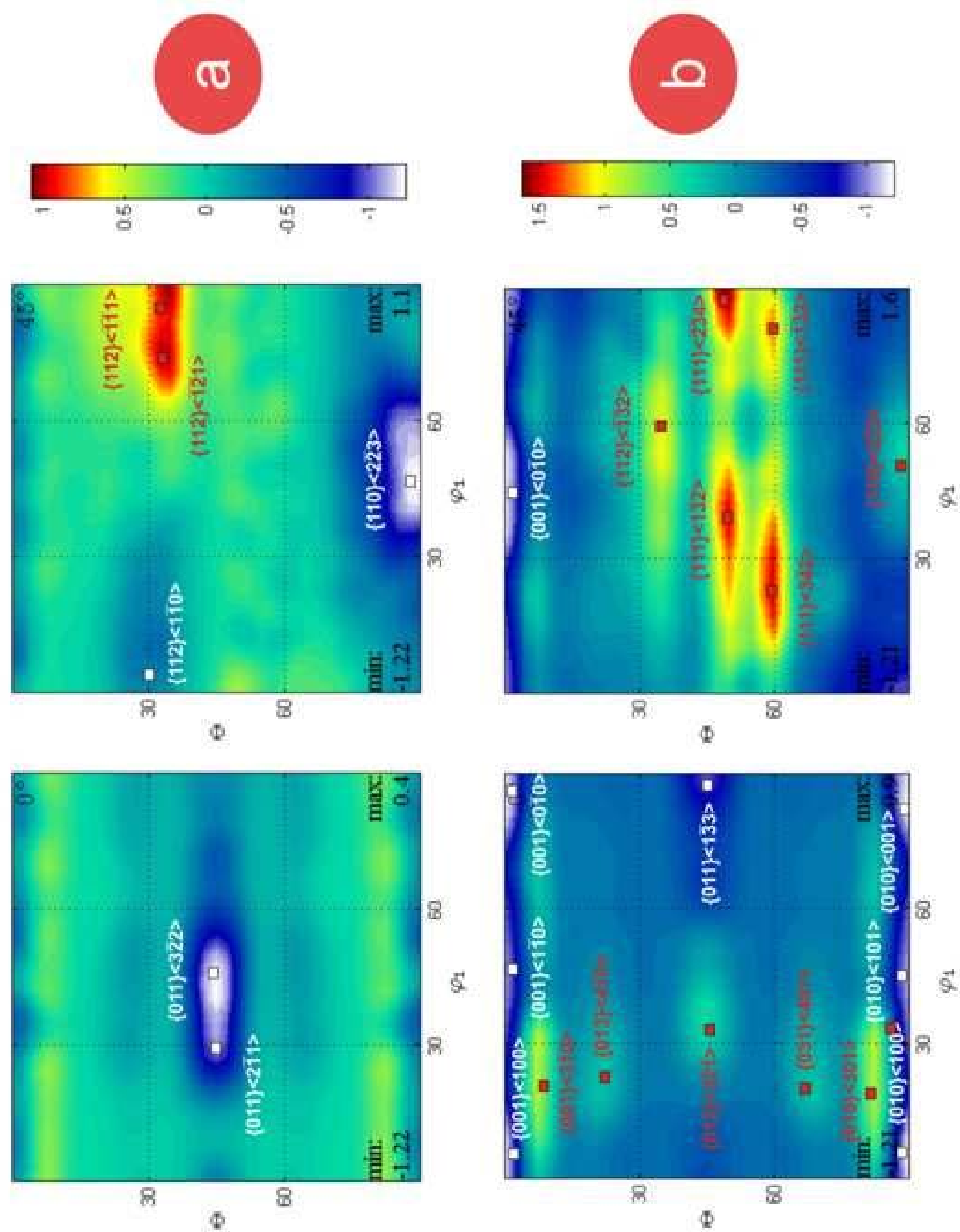

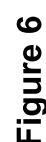



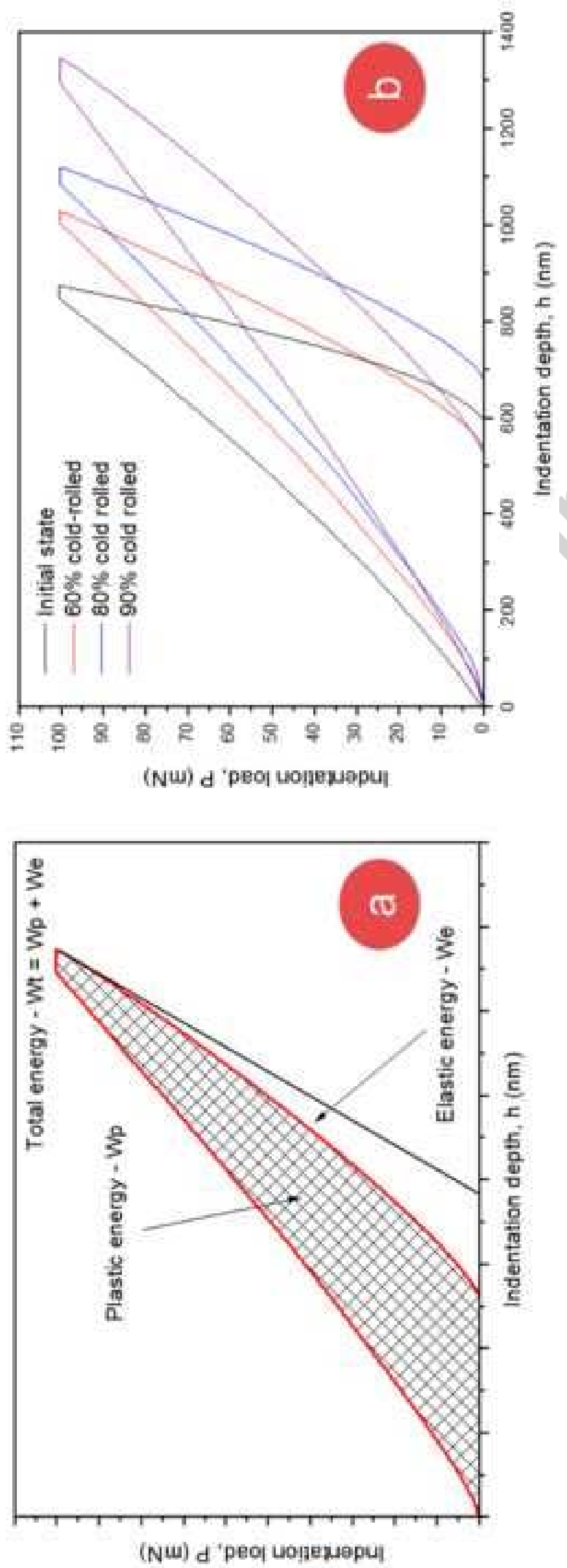

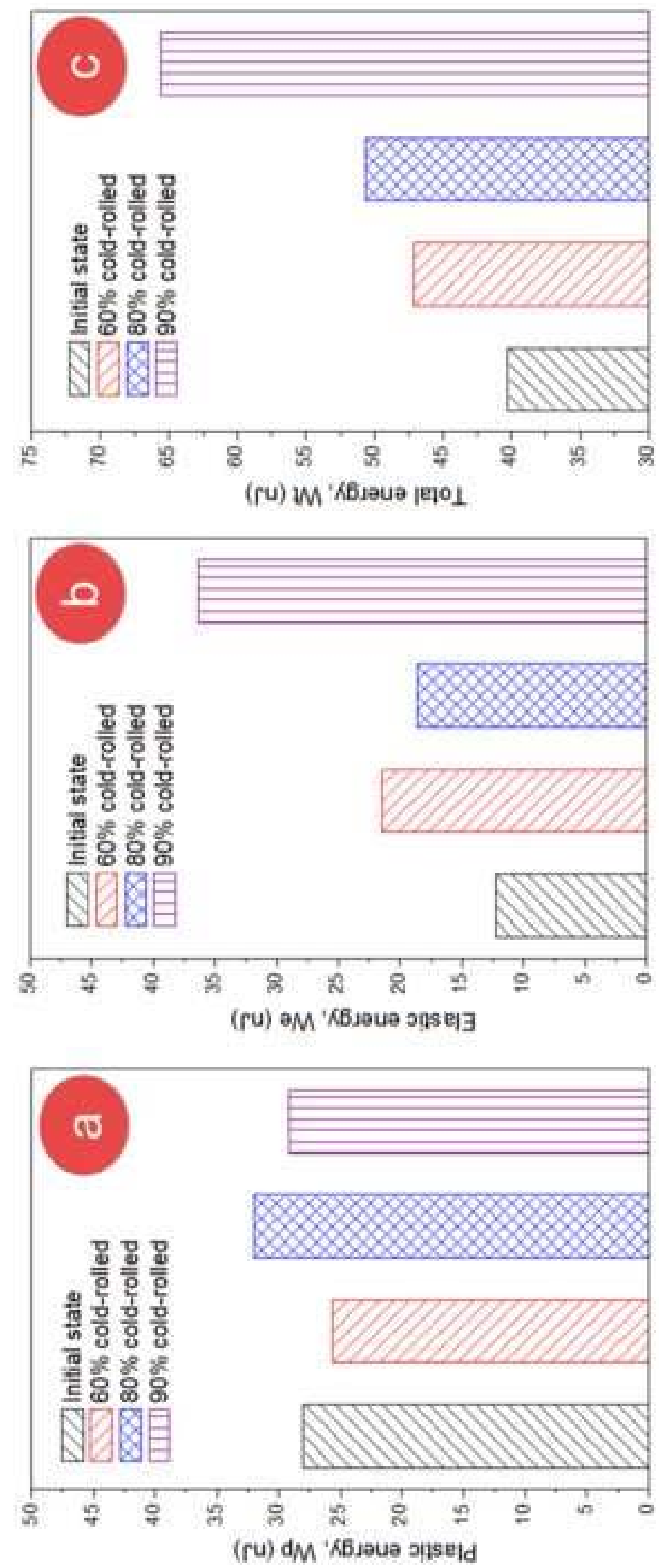

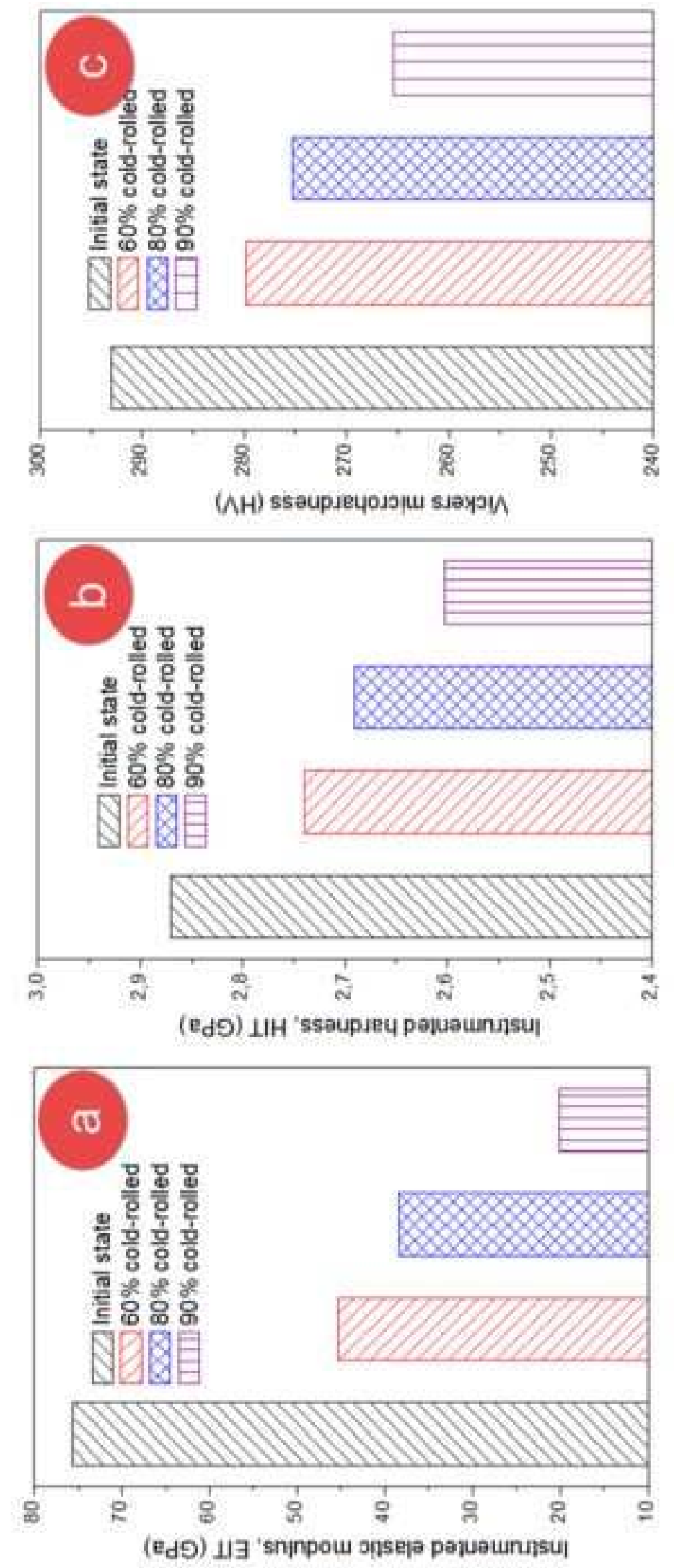